Retrospective Study

\title{
Cervical Spinal Cord Stimulation: An Analysis of 23 Patients with Long-term Follow-up
}

Tilman Wolter, MD, and Kristin Kieselbach, MD

From:
Interdisciplinary Pain Centre,
University Hospital Freiburg,
Freiburg, Germany
Address correspondence:
Tilman Wolter, MD
University Hospital Freiburg
Interdisciplinary Pain Centre
Breisacherstr. 64
Freiburg, Germany
freiburg.de
E-mail: tilman.wolter@uniklini-
Pisclaimer: There was no external
funding in the preparation of this
manuscript.
Conflict of interest: Dr. Wolter has
received a single travel grant from
Boston Scientific in 2010.

Manuscript received: $12 / 15 / 2011$
Revised manuscript received:
o1/26/2012
Accepted for publication: o2/08/2012
Free full manuscript:
www.painphysicianjournal.com

Background: For more than 3 decades, spinal cord stimulation has successfully been employed to treat neuropathic pain. Cervical spinal cord stimulation, despite now being standard in many hospitals, has only rarely been subjected to a critical review within the literature.

Objectives: The aim of this study was to determine the efficacy of cervical spinal cord stimulation (SCS) in a representative clinical sample. We also wanted to evaluate how factors such as stimulation parameters, unwanted paresthesia of the trunk and legs, and changes in paresthesia status due to head movement and how they affect SCS effectiveness.

Study design: Retrospective study.

Setting: Academic university interdisciplinary pain center.

Methods: We reviewed the records of patients who had been treated at our institution with cervical neurostimulators from November 1, 2001 through October 31, 2011. Information regarding age, gender, diagnosis, age at time of implantation, duration of disease, lead position, hardware in use, revision operations, and stimulation parameters were recorded. In addition, a short telephone interview was conducted, which contained the following items: pain scores on the numeric analog scale (NAS) with and without stimulation, time intervals of stimulation, paresthesia coverage, changes in paresthesia coverage by head movements, unwanted paresthesia of the trunk and legs, treatment satisfaction, and medication intake.

Results: Twenty-three patients were treated. Eighteen patients proceeded to an implantable pulse generator (IPG) implant. In one patient, the system was removed after 4 years despite optimal function, because the patient was no longer experiencing pain. Average NAS pain scores were 6.8 (range 5.5 - 10.0, standard deviation [SD] 1.7) without, and 2.8 (range 0 7.5, SD 2.2) with neurostimulation. Fourteen revisions (5 due to lead dislocation, 5 due to lead breakage and 4 IPG revisions) were necessary in 9 of the 18 patients during a mean follow-up of 6.2 years. Most patients reported complete paresthesia coverage. Four patients reported unwanted paresthesia of the trunk or lower limb and 11 patients reported changes in paresthesia with head movements. In both instances, pain reduction was not affected.

Limitations: Retrospective study.

Conclusions: Cervical spinal cord stimulation appears to be effective in the treatment of neuropathic upper limb pain. Complications are not significantly more frequent than in SCS for lower limb pain. Changes in paresthesia with head movements and unwanted paresthesia did not affect the outcome.

Key words: Spinal cord stimulation, cervical, neuropathic pain, clinical efficacy, paresthesia, paresthesia coverage, changes in paresthesia, brachial plexus lesion, nerve root avulsion, stimulation parameters

Pain Physician 2012; 15:203-212 
or more than 3 decades spinal cord stimulation (SCS) has been successfully employed for the treatment of chronic neuropathic pain syndromes (1). In failed back surgery syndrome (2-6), complex regional pain syndrome (CRPS) (7-9) and postzosteric neuralgia (10-11) favorable clinical outcomes have been reported. A recent multi-center study showed improved pain relief, quality of life, functional capacity, and greater treatment satisfaction in patients treated with SCS compared to patients treated with conventional medical treatment for neuropathic pain (12). In a recent comprehensive review, level II-1 or II-2 evidence was found in managing the neuropathic pain of postlumbar surgery syndrome patients (13).

Despite the vast literature on SCS as a treatment option for leg pain, there is a relative paucity of literature regarding SCS as a treatment for upper limb pain.

Some of the large SCS studies $(1,14)$ also comprise a number of patients with cervical SCS. These studies, however, are focussed on the outcome of SCS in general for a particular pathological condition, such as CRPS $(8,11)$. Furthermore, details about cervical neurostimulation are missing. However, cervical SCS, despite differing from thoracolumbar stimulation in several biomechanical, neurophysiological, and surgical aspects, has only rarely been studied separately.

In particular, the consistency and completeness of paresthesia coverage, the amount of device-related complications, and the extent of the SCS-induced painrelieving effect, as well as by which factors the latter is influenced by cervical SCS, have only anecdotally been reported in the literature. Moreover, data is sparse on how cervical SCS devices, in contrast to thoracolumbar devices, are programmed and how this programming affects outcome.

\section{Methods}

\section{Patients}

The Ethics Committee of the University Hospital, Freiburg, Germany approved this study. All patients who had been treated at our institution from November 1, 2001 through October 31, 2011 were entered into the study if they presented for a new implant or for adjustment of a pre-existing SCS device.

Charts were reviewed regarding personal data, diagnoses, duration of disease, date of electrode and IPG implant, type of implants, operative revisions, preoperative and postoperative pain scores on an 11 point (0-
10) numeric analog scale (NAS). X-rays were reviewed regarding lead location.

A short telephone interview was conducted containing the following items: daily duration of stimulation, pain scores on the NAS with and without stimulation, time intervels of stimulation, paresthesia coverage, changes in paresthesia coverage by head movements, unwanted paresthesia of the trunk and legs, treatment satisfaction, and medication intake.

\section{Statistical Analysis}

A computer software package (GraphPad Prism, Version 5.01, GraphPad Software, Inc. La Jolla, CA) was used to conduct the statistical analyses. Descriptive statistics were initially applied to all measures. To calculate the statistical significance of the differences in mean NAS scores, the Wilcoxon matched pairs test was used. The Mann-Whitney $U$ test was used to compare mean pain ratings in different groups. A $P<0.05$ was considered statistically significant.

\section{Results}

\section{Patients}

Twenty-three patients (19 men and 4 women), with a mean age of 54.4 years (range 34 - 78 years, standard deviation [SD] 10.8 years) were included in this study. Eighteen patients had a successful trial and subsequent implantable pulse generator (IPG) implantation. Four of these patients could not be interviewed (Fig. 1). The interviews were conducted 5.8 years (the mean) after SCS implantation (range 0.4 - 21 years, SD 5.2 years) and 13.1 years after onset of chronic pain (range 3 - 24 years, SD 6.7 years). Diagnoses and patient characteristics are given in Tables 1 and 2.

\section{Interventions}

Twenty-one of the 23 patients studied had percutaneous-type leads. These had been inserted at the T2/3 level as described previously (15). Two patients had paddle-type electrodes that had been implanted via laminotomy. In one patient, likely due to intraspinal scarring, the electrode could not be advanced beyond the level of $\mathrm{C} 6$, where it did not exert adequate paresthesia coverage. After a number of frustrating efforts to direct the lead to a more cranial position, the operation was discontinued. In 4 patients the electrode was removed after a testing phase of a median 11 days (range 7 - 23 days). Eighteen patients had a successful trial phase and received an IPG after a mean 11.1 days 


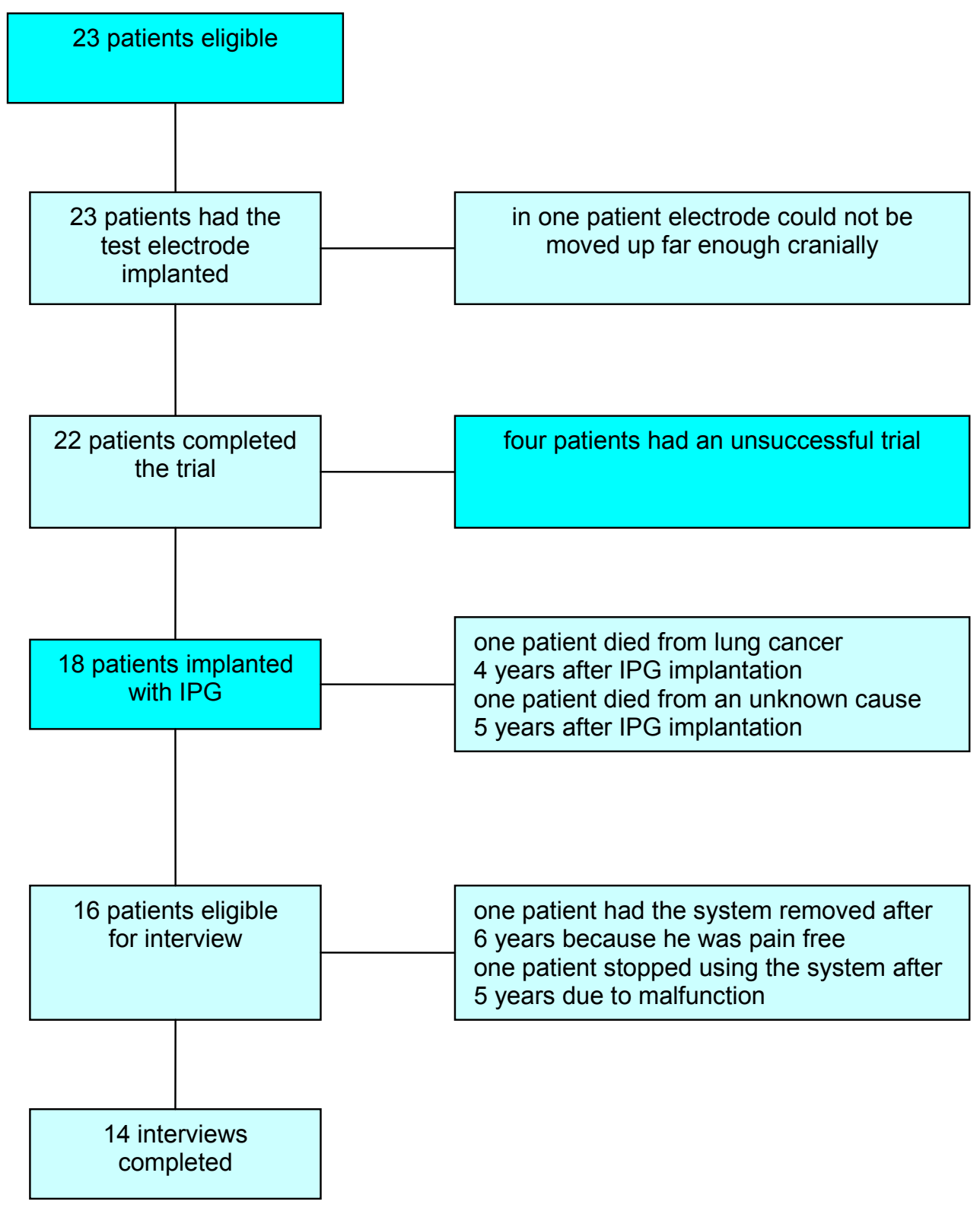

Fig. 1. Patient eligibility and analysis

(range 7 - 22 days). Hardware characteristics and stimulation parameters are given in Table 3.

\section{Outcome}

Mean NAS pain score without stimulation was 6.8 (range 5.5 - 10, SD 1.7). Under stimulation this value de- creased to 2.8 (range 0 - 7.5, SD 2.2) (Fig. 2).

Mean daily stimulation time was 14.4 hours (range 1 - 24 hours, SD 10.4 hours). Seven patients stimulated continuously and 7 patients stimulated intermittently. Of those patients using intermittent stimulation 2 stimulated only at daytime and 5 at day and nighttime 
Pain Physician: May/June 2012; 15:203-212

Table 1. Patient characteristics of patients with a successful trial and subsequent IPG implantation, * at time of interview

\begin{tabular}{|c|c|c|c|c|}
\hline Patient & Age*, Gender & Diagnosis & $\begin{array}{l}\text { Time Since Onset } \\
\text { of Pain*/ Years }\end{array}$ & $\begin{array}{c}\text { Time Since SCS } \\
\text { Implantation*/ Years }\end{array}$ \\
\hline 1 & $56, \mathrm{w}$ & Raynaud`s-Syndrome & 8 & 6.0 \\
\hline 2 & $63, \mathrm{~m}$ & $\begin{array}{l}\text { causalgia of the hand after soft tissue injury } \\
\text { with amputation of the fifth finger }\end{array}$ & 19 & 6.3 \\
\hline 3 & $56, \mathrm{~m}$ & shoulder pain & 24 & 3.3 \\
\hline 4 & $78, \mathrm{~m}$ & phantom pain after upper arm amputation & 22 & 20.8 \\
\hline 5 & $51, \mathrm{w}$ & CRPS upper extremity & 5 & 3.1 \\
\hline 6 & $34, w$ & $\begin{array}{l}\text { phantom pain after soft tissue injury with } \\
\text { amputation of the second finger }\end{array}$ & 3 & 0.4 \\
\hline 7 & $50, \mathrm{~m}$ & $\begin{array}{l}\text { buzz saw injury, } \\
\text { multiple operations, } \\
\text { radial neuropathy }\end{array}$ & 13 & 6.8 \\
\hline 8 & $52, \mathrm{~m}$ & causalgia & 11 & 4.4 \\
\hline 9 & $68, \mathrm{~m}$ & $\begin{array}{l}\text { Crest Syndrome, phantom pain second and } \\
\text { third finger }\end{array}$ & 7 & 1.2 \\
\hline 10 & $58, w$ & phantom pain second finger & 8 & 6.5 \\
\hline 11 & $59, \mathrm{~m}$ & ulnar neuropathy & 11 & 8.7 \\
\hline 12 & $65, \mathrm{~m}$ & cervicobrachialgia, had ventral fusion C $4 / 5$ & 20 & 9.5 \\
\hline 13 & $46, \mathrm{~m}$ & ulnar neuropathy, had multiple operations & 19 & 3.1 \\
\hline 14 & $47, \mathrm{~m}$ & $\begin{array}{l}\text { shoulder pain, plexus lesion, had shoulder } \\
\text { prosthesis }\end{array}$ & 13 & 1.1 \\
\hline 15 & $54, \mathrm{~m}$ & incomplete plexus lesion & 18 & 9.0 \\
\hline 16 & $43, \mathrm{~m}$ & phantom pain & 14 & 5.3 \\
\hline 17 & $56, \mathrm{~m}$ & cervicobrachialgia, had frykholm operation & 10 & 9.7 \\
\hline \multirow[t]{2}{*}{18} & $45, \mathrm{~m}$ & $\begin{array}{l}\text { cervicobrachialgia, } \\
\text { radiculopathy C6-C8 }\end{array}$ & 8 & 6.3 \\
\hline & $\begin{array}{l}\text { 54.4 (SD 10.8) years } \\
4 \text { female,14 male }\end{array}$ & & 12.9 (SD 6.1) years & $6.2(\mathrm{SD} 4.7)$ years \\
\hline
\end{tabular}

Table 2. Diagnoses, stimulation characteristics and reasons for trial failure, n.a. $=$ not applicable

\begin{tabular}{|c|c|c|c|c|c|c||}
\hline Patient & $\begin{array}{c}\text { Age, } \\
\text { Gender }\end{array}$ & Diagnosis & Lead Type & $\begin{array}{c}\text { Position of } \\
\text { Lead Tip }\end{array}$ & $\begin{array}{c}\text { Duration of Test } \\
\text { Phase/Days }\end{array}$ & $\begin{array}{c}\text { Reason For Trial } \\
\text { Failure }\end{array}$ \\
\hline 19 & $64, \mathrm{~m}$ & $\begin{array}{c}\text { phantom pain } \\
\text { after upper arm amputation }\end{array}$ & 4 pole & $\mathrm{C} 3$ & 14 & $\begin{array}{c}\text { insufficient pain reduction } \\
\text { despite optimal paraesthesia }\end{array}$ \\
\hline 20 & $65, \mathrm{~m}$ & $\begin{array}{c}\text { plexus lesion with } \\
\text { nerve root avulsion }\end{array}$ & 4 pole & $\mathrm{C} 3$ & 8 & $\begin{array}{c}\text { unpleasant character of } \\
\text { stimulation }\end{array}$ \\
\hline 21 & $67, \mathrm{~m}$ & $\begin{array}{c}\text { ulnar neuropathy, } \\
\text { had multiple operations }\end{array}$ & 4 pole & $\mathrm{C} 3$ & 7 & $\begin{array}{c}\text { insufficient pain reduction } \\
\text { despite optimal paraesthesia }\end{array}$ \\
\hline 22 & $58, \mathrm{~m}$ & $\begin{array}{c}\text { plexus lesion with } \\
\text { nerve root avulsion }\end{array}$ & 4 pole & C 5 & 23 & $\begin{array}{c}\text { insufficient pain reduction } \\
\text { despite optimal paraesthesia }\end{array}$ \\
\hline 23 & $40, \mathrm{~m}$ & $\begin{array}{c}\text { plexus lesion with nerve root } \\
\text { avulsion, shoulder pain }\end{array}$ & 4 pole & C 6 & n.a. & $\begin{array}{c}\text { impossibility of sufficient lead } \\
\text { positioning }\end{array}$ \\
\hline
\end{tabular}


Cervical Spinal Cord Stimulation

Table 3. Stimulation characteristics, * from distal to proximal, **percutaneous type.

\begin{tabular}{|c|c|c|c|c|c|c|c|}
\hline Patient & Lead & IPG & $\begin{array}{l}\text { Position of } \\
\text { Lead Tip }\end{array}$ & Polarity* & $\begin{array}{c}\text { Impulse } \\
\text { Duration/ } / \mathrm{s}\end{array}$ & Frequency/HZ & Amplitude/V \\
\hline 1 & 4 pole & ITREL III & $\mathrm{C} 2$ & $+0-0$ & 300 & 45 & 1.2 \\
\hline 2 & 4 pole & ITREL III & C 5 & $00-+$ & 120 & 70 & 4.8 \\
\hline 3 & 8 pole & Synergy & C 3 & $-00+0000$ & 210 & 80 & 2.1 \\
\hline 4 & 4 pole & ITREL III & C 5 & $-00+$ & 270 & 75 & 3.5 \\
\hline 5 & 8 pole & Synergy & $\mathrm{C} 4$ & n.d. & n.d & n.d & n.d \\
\hline 6 & 8 pole & Restore Ultra & $\mathrm{C} 4$ & $00-+0000$ & 180 & 100 & 2.4 \\
\hline 7 & 4 pole & ITREL III & C 5 & --++ & 270 & 50 & 1.9 \\
\hline 8 & 4 pole & ITREL III & C 4 & $-00+$ & 300 & 60 & 2.1 \\
\hline 9 & 8 pole & Restore Ultra & C 3 & $0000+00-$ & 240 & 80 & 0.5 \\
\hline 10 & 4 pole & ITREL III & C 5 & ++-- & 300 & 70 & 2.2 \\
\hline 11 & 4 pole & ITREL III & $\mathrm{C} 4$ & --++ & 210 & 30 & 1.3 \\
\hline 12 & 4 pole & ITREL III & C 5 & $-00+$ & 360 & 70 & 1.8 \\
\hline 13 & 8 pole & ITREL III & C 5 & $000-00+0$ & 360 & 120 & 1.1 \\
\hline 14 & 8 pole & Prime Advanced & $\mathrm{C} 2$ & +--00000 & 240 & 100 & 2.3 \\
\hline 15 & paddel & ITREL III & C 5 & $000-00+0$ & 180 & 90 & 2.9 \\
\hline 16 & paddel & Synergy & C 5 & +--00000 & 180 & 75 & 2.7 \\
\hline 17 & 4 pole & ITREL III & C 5 & n.d. & 180 & 65 & 2.1 \\
\hline \multirow[t]{2}{*}{18} & 4 pole & ITREL III & C 5 & $00-+$ & n.d. & n.d. & n.d \\
\hline & $\begin{array}{c}10 \times 4 \text { pole**} \\
6 \times 8 \text { pole }^{* *} \\
2 \times \text { paddle }\end{array}$ & $\begin{array}{c}12 \text { x ITREL III } \\
3 \text { x Synergy } \\
\text { 2x Restore Ultra } \\
1 \text { x Prime }\end{array}$ & $\begin{array}{l}2 x_{C} 2,2 x C 3 \\
4 x C 4,10 x C 5\end{array}$ & $\begin{array}{c}\text { 8x narrow, } \\
\text { 8x broad } \\
\text { dipole }\end{array}$ & $\begin{array}{c}\text { mean } 244 \\
(\text { SD 69) }\end{array}$ & $\begin{array}{c}\text { mean } 74 \\
(\mathrm{SD} 22)\end{array}$ & $\begin{array}{c}\text { mean } 2.2 \\
(\mathrm{SD} 1.0)\end{array}$ \\
\hline
\end{tabular}

(mean 4.9 hours). There were no statistically significant differences between those patients performing intermittent stimulation and those stimulating continuously.

Eleven patients reported complete paresthesia coverage, and 3 patients reported incomplete paresthesia coverage. The neck was specified in 2 cases when asked in which area paresthesia was missing. There were no statistically significant differences in NAS scores between patients with and without complete paresthesia coverage.
Eleven patients reported that their paresthesia changed with head movements and 7 of these patients did not find this bothersome. There were no statistically significant differences in NAS scores between these patients with or without unpleasant changes in paresthesia.

Four patients quoted undesirable paresthesia of the trunk and/ or legs even though they did not find this bothersome. 


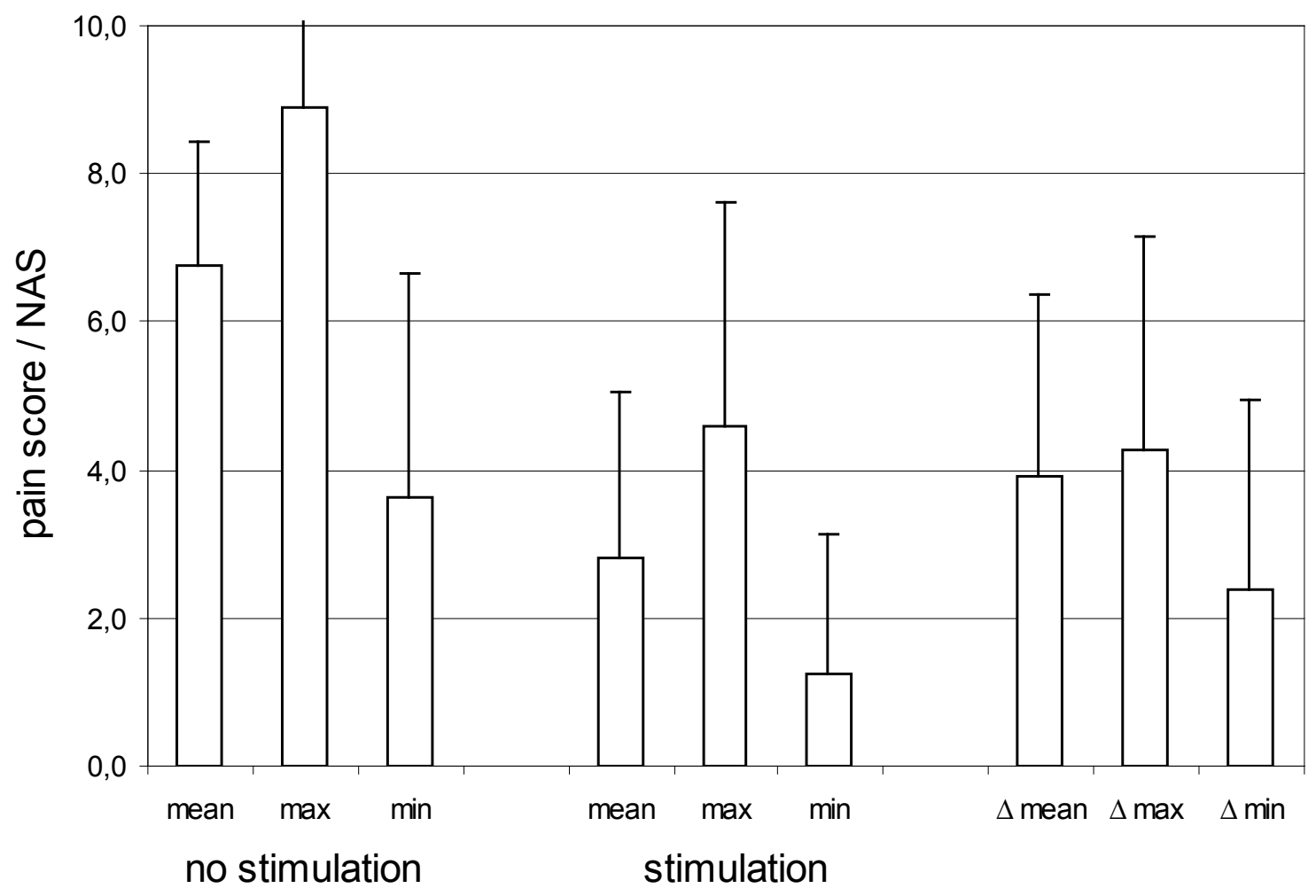

Fig. 2. Mean, maximal and minimal pain scores (NAS) without stimulation, with stimulation and the difference between these scores due to stimulation

\section{Stimulation Patterns}

Among those patients who answered the interview $(n=14)$, overall mean duration of stimulation was 14.4 hours (range 1 - 24 hours, SD 10.4 hours). Seven patients used their stimulation system continuously 24 hours/day and 7 patients used it intermittently. In those patients performing intermittent stimulation median duration of daily use was 3 hours. Five patients used the neurostimulation system considerably above the perception threshold, 8 patients used it slightly above threshold, and one patient used it below perception threshold.

Eight patients used electrode polarities with a distance between the anode and the cathode of at least one pole, while eight other patients used polarities with the anode directly next to the cathode. Those patients with a broader dipole had longer impulse durations (mean 277 microseconds versus 210 microseconds,
$P=0.0446)$. There were no statistically significant differences in stimulation frequency or amplitude between these 2 patient groups.

\section{Medication intake}

Nine patients regularly took analgesics. Two patients took only nonsteroidal anti-inflammatory drugs (NSAID). One patient took an NSAID combined with a strong opioid and an antidepressant. Two patients took strong opioids alone. One patient took a combination of a weak opioid, an anticonvulsant, and an antidepressant and 3 patients took antidepressants as monotherapy. Five patients took no analgesic drugs.

\section{Complications and operative revisions}

There were no severe complications such as infection or neurological deficit. In the 18 patients who had 
been implanted with an IPG, 5 lead dislocations and 5 lead breakages occurred. In one patient the IPG had to be locally revised due to pain at the pocket site. For the same reason in another patient, the IPG was first relocated from the abdominal to the subclavicular area and 5 months later the IPG was locally revised due to persisting pain. One patient had one IPG revision due to pain at the pocket site and 3 lead revisions, 2 due to electrode breakage and one due to dislocation $\ln 2$ patients the IPG was changed due to battery discharge (after 4 and 9 years). In total, 14 "unscheduled" re-operations were necessary in 9 of the 18 patients during a mean follow-up of 6.2 years.

\section{Side Effects, Handling of the Device and Treatment Satisfaction}

Four patients reported pain at the IPG site as an unpleasant side effect. Ten patients reported that they had had no unpleasant side effects.

The handling of the device was rated to be "very good" by 10 patients and to be "good" by 4 patients. None of the patients rated the handling of the device as "bad" or "very bad."

Nine patients were "very content," 3 patients were "content," 2 patients were "undecided." No patient was "discontent" or "very discontent" with SCS.

Thirteen patients (93\%) agreed that they would have the stimulator implanted again, while one patient would not undergo implantation again.

\section{Discussion}

The present study shows that cervical SCS is effective in relieving pain in a representative clinical sample, as the present data on pain intensity indicate. In our patients, average NAS scores were decreased by more than $50 \%$. The long follow-up (6 years) denotes that this effect is stable over time. Moreover, we found that in single patients, pain levels under stimulation can recede completely, allowing explantation of the system.

Paresthesia coverage was complete in most of the patients despite the use of 4-pole or eight-pole percutaneous-type electrodes, generating a longitudinal stimulation, but not multi-column tripolar leads as those which have been successfully used for back pain coverage in patients with failed back surgery syndrome (FBSS) (16-17). Interestingly, we found that in those patients with a distance between anode and cathode of one or more poles, the impulse duration was significantly longer. However, this factor did not affect the extent of pain relief. It is likely that with cervical SCS, incomplete paresthesia coverage occurs less frequently than with SCS for FBSS, because in patients treated with cervical SCS, neck pain is less common. However, we also found complete paresthesia coverage in patients with less localized pain as, for example, in one patient with shoulder pain and another patient with "failed neck surgery syndrome" (15). Most of our patients reported changes in paresthesia with head movements, though in some patients this effect diminished within a few months. The majority of these patients, however, did not find this effect bothersome.

Cervical SCS differs from thoracolumbar SCS for lower extremity pain in some respects. First, due to the higher mobility of the cervical spine, changes in paresthesia elicited by SCS are more likely. To date, there are no studies addressing this question. Second, due to the different anatomy of the dorsal columns, unwanted paresthesia of the trunk and the lower extremity is possible. In a series of 5 patients, Vallejo et al (15) reported paresthesia of the whole body in 3 patients. Surprisingly, this was not undesirable because these patients had pain in the lower parts of their body too. The question as to why not all patients with cervical SCS report (unpleasant) whole body stimulation might be best answered by considering the findings of Feirabend et al (18). In an outstanding study on the morphometry of the dorsal columns, they concluded that the fiber density increases from medial to lateral. With lower stimulation intensities more lateral fibers would be recruited, thus leading to a perceived stimulation in the upper extremity. In contrast, with stronger stimulation, more medial fibers would be recruited, thus resulting in stimulation of the trunk and/or the legs.

Apart from a number of case reports or small case series (19-24), cervical SCS has not been exclusively studied. However, cervical SCS has frequently been subject to investigation in the context of clinical studies focusing on SCS (cervical and thoracolumbar) for particular pathologies.

In a study of SCS in 29 CRPS patients, with 16 cases of CRPS of the upper limb, an excellent efficacy of SCS for both cervical and thoracolumbar lead position was found. However, the effects of treatment were not calculated separately (8). In another study of 36 CRPS patients treated with SCS, Forouzanfar et al (25) found similar treatment effects in 19 patients with cervical and 17 patients with thoracolumbar SCS. Bennett et al (14) studied the effects of SCS in 101 patients with CRPS I, including 49 patients with CRPS of the upper limb, and found dual lead octopolar systems to be more ef- 
fective than singe lead quadripolar systems.

In a study on SCS for the upper limb, Robaina et al (26) reported on 11 patients; 8 patients with CRPS and 3 patients with Raynaud disease. Ten of the patients had good or excellent results. Thermographic and plethysmographic changes were observed in patients with CRPS as well as in patients with Raynaud syndrome, and an increase in blood flow seemed to correlate to the amount of pain relief provided. In 1994, Francaviglia et al (27) reported on 15 patients with Raynaud phenomenon secondary to progressive systemic scleroderma who were treated with cervical SCS. The authors concluded that SCS was an effective therapy for patients with progressive systemic scleroderma and Raynaud phenomenon because of its beneficial effects on Raynaud episodes, ulcers, pain, vascular sclerosis, and hand function (27). Since then, similar results have been published in a number of case reports on cervical SCS for vasospastic diseases $(19,22,24)$.

Plexus lesions, particularly when accompanied by cervical root avulsion, have been controversially regarded as an indication for cervical SCS. There have been occasional reports of good or excellent outcomes after cervical SCS for plexus lesions with cervical nerve root avulsion. In a case series of 4 patients with pain resulting from brachial plexus avulsion, a steady decrease in pain strength totaling approximately 3 points on the NAS over 6 months was found (21). In these patients a specially designed 7-contact electrode was used with the top contact at the C2 level. Brill et al (23) reported excellent outcomes following SCS treatment in 2 patients who, as the authors stated, probably had partial injuries of the nerve roots (23).

Our series, in contrast, demonstrates a number of failed SCS trials in patients with brachial plexus lesions and nerve root avulsions. One could argue that SCS in cases of nerve root avulsion (which are associated with plexus lesions in about $70 \%$ of the cases [28]) cannot be efficient due to irreversible damage of the nerve structure where stimulation usually is exerted. On the other hand, electrode placement cephlad to the lesion in these cases could ensure successful stimulation. In our series, the electrode was moved up at least one or 2 levels cranially \{cephalad?\} to the lesion. However, SCS still had no sufficient effect in 4 of 5 patients with cervical root avulsions, despite optimal paresthesia coverage. Moreover, we encountered technical problems, likely due to intraspinal scarring in one case. Taken together, our series raises doubts about the efficacy of SCS for cervical plexus injuries with nerve root avul- sion. Likewise, a recent review on candidate selection for SCS treatment listed nerve root avulsion, stretching, or injury among disease characteristics that predict a low probability of successful pain reduction (29). In our patients, trial failure was not due to incomplete coverage, which might have been overcome with the use of tripolar fields. Instead, failure was due to insufficient pain reduction despite complete paresthesia coverage.

The complication rate in our study was within the range reported in the literature. In a study on hardware failure modes, conducted on 298 patients over a five years period, Rosenow et al (30) found a significantly higher revision rate in cervical SCS systems than in thoracic $(63 \%$ versus $41.7 \%)$. Migration followed by lead breakage and poor coverage was the most frequent cause of repeat surgery (30).

The present study is limited by its retrospective design and relatively small number of patients, although the number of patients is large enough to demonstrate clinically meaningful effects. Due to the heterogeneity of pathologies treated with cervical SCS, our series does not allow us to draw definite conclusions about cervical SCS for singular pathologies. Regarding cervical SCS in general, however, some insight can be extracted from our data.

A significant strength of this study is the quality of the data, which was obtained from all eligible patients. This was ensured using a telephone interview where patients' queries could be clarified immediately. Patients who had ceased to perform stimulation, even for only a short period of time, for instance, were excluded from the analysis. We believe that the questions regarding stimulation can be best answered by the patient at a time when he or she is currently using the device. This method of gathering data likely leads to a more accurate perspective, as compared to retrospective data collection methods. A further strength of the study is that all relevant factors attributable to the pain-relieving effect of spinal cord stimulation were determined.

\section{Conclusion}

In summary, cervical SCS appears to be a safe and efficacious treatment option for upper limb neuropathic pain. Unwanted paresthesia of the trunk and the lower limbs, or changes in paresthesia, do not halter the efficacy of stimulation. Complication rates for cervical SCS seem to be higher than those reported for thoracolumbar SCS. However, in our series, complication rates were comparable to previously published data. In our view, particularly circumscribed pain due to nerve lesions is 
a promising indication for cervical SCS. Brachial plexus lesions, if associated with nerve root avulsions, do not profit from cervical SCS, at least as long as solely longitudinal stimulation systems are used. In peripheral neuropathic pain or cervicobrachialgia, however, with SCS using percutaneous-type electrodes, effective pain relief can be achieved.

\section{References}

1. Kumar K, Hunter G, Demeria D. Spinal cord stimulation in treatment of chronic benign pain: Challenges in treatment planning and present status, a 22 -year experience. Neurosurgery 2006; 58:481496; discussion 481-496.

2. Meglio M, Cioni B, Rossi GF. Spinal cord stimulation in management of chronic pain. A 9-year experience. J Neurosurg 1989; 70:519-524.

3. De La Porte C, Van de Kelft E. Spinal cord stimulation in failed back surgery syndrome. Pain 1993; 52:55-61.

4. Hassenbusch SJ, Stanton-Hicks M, Covington EC. Spinal cord stimulation versus spinal infusion for low back and leg pain. Acta Neurochir Suppl 1995; 64:109115 .

5. Ohnmeiss DD, Rashbaum RF, Bogdanffy GM. Prospective outcome evaluation of spinal cord stimulation in patients with intractable leg pain. Spine (Phila Pa 1976) 1996; 21:1344-50; discussion 1351.

6. Kumar K, Taylor RS, Jacques L, Eldabe S, Meglio M, Molet J, Thomson S, O'Callaghan J, Eisenberg E, Milbouw G, Buchser E, Fortini G, Richardson J, North RB. Spinal cord stimulation versus conventional medical management for neuropathic pain: A multicentre randomised controlled trial in patients with failed back surgery syndrome. Pain 2007; 132:179-188.

7. Kemler MA, Reulen JP, Barendse GA, van Kleef $M$, de Vet $H C$, van den Wildenberg FA. Impact of spinal cord stimulation on sensory characteristics in complex regional pain syndrome type I: A randomized trial. Anesthesiology 2001; 95:72-80.

8. Harke H, Gretenkort P, Ladleif HU, Rahman S. Spinal cord stimulation in sympathetically maintained complex regional pain syndrome type I with severe disability. A prospective clinical study. Eur J Pain 2005; 9:363-373.

9. Kemler MA, de Vet HC, Barendse GA, van den Wildenberg FA, van Kleef $M$. Spinal cord stimulation for chronic re- flex sympathetic dystrophy--five-year follow-up. N Engl J Med 2006; 354:23942396.

10. Meglio M, Cioni B, Prezioso A, Talamonti G. Spinal cord stimulation (SCS) in the treatment of postherpetic pain. Acta Neurochir Suppl (Wien) 1989; 46:65-66.

11. Harke H, Gretenkort P, Ladleif HU, Koester P, Rahman S. Spinal cord stimulation in postherpetic neuralgia and in acute herpes zoster pain. Anesth Analg 2002; 94:694-700; table of contents.

12. Kumar K, Taylor RS, Jacques L, Eldabe $S$, Meglio M, Molet J, Thomson S, O'Callaghan J, Eisenberg E, Milbouw G, Buchser E, Fortini G, Richardson J, North RB. The effects of spinal cord stimulation in neuropathic pain are sustained: A 24-month follow-up of the prospective randomized controlled multicenter trial of the effectiveness of spinal cord stimulation. Neurosurgery 2008; 63:762-70; discussion 770.

13. Manchikanti L, Boswell MV, Datta S, Fellows B, Abdi S, Singh V, Benyamin RM, Falco FJ, Helm S, Hayek SM, Smith HS. Comprehensive review of therapeutic interventions in managing chronic spinal pain. Pain Physician 2009; 12:E123-E198.

14. Bennett D, Alo K, Oakley J, Feler C. Spinal cord stimulation for complex regional pain syndrome I [RSD]: A retrospective multicenter experience from 1995 to 1998 of 101 patients. Neuromodulation 1999; 2:202-210.

15. Vallejo R, Kramer J, Benyamin R. Neuromodulation of the cervical spinal cord in the treatment of chronic intractable neck and upper extremity pain: A case series and review of the literature. Pain Physician 2007; 10:305-311.

16. Buvanendran A, Lubenow TJ. Efficacy of transverse tripolar spinal cord stimulator for the relief of chronic low back pain from failed back surgery. Pain Physician 2008; 11:333-338.

17. Rigoard P, Delmotte A, D'Houtaud S, Misbert L, Diallo B, Roy-Moreau A, Durand S, Royoux S, Giot JP, Bataille B.
Back pain: A real target for spinal cord stimulation? Neurosurgery 2011. \{incomplete information\}

18. Feirabend HK, Choufoer H, Ploeger S, Holsheimer J, van Gool JD. Morphometry of human superficial dorsal and dorsolateral column fibres: Significance to spinal cord stimulation. Brain 2002; 125:1137-1149.

19. Benyamin R, Kramer J, Vallejo R. A case of spinal cord stimulation in Raynaud's Phenomenon: Can subthreshold sensory stimulation have an effect? Pain Physician 2007; 10:473-478.

20. Neuhauser B, Perkmann R, Klingler PJ, Giacomuzzi S, Kofler A, Fraedrich G. Clinical and objective data on spinal cord stimulation for the treatment of severe Raynaud's phenomenon. Am Surg 2001; 67:1096-1097.

21. Piva B, Shaladi A, Saltari R, Gilli G. Spinal cord stimulation in the management of pain from brachial plexus avulsion. Neuromodulation 2003; 6:27-31.

22. Sibell DM, Colantonio AJ, Stacey BR. Successful use of spinal cord stimulation in the treatment of severe Raynaud's disease of the hands. Anesthesiology 2005; 102:225-227.

23. Brill S, Aryeh IG. Neuromodulation in the management of pain from brachial plexus injury. Pain Physician 2008; 11:8185.

24. Wolter T, Kieselbach K. Spinal cord stimulation for Raynaud's Syndrome: Longterm alleviation of bilateral pain with a single cervical lead. Neuromodulation 2011; 14:229-234.

25. Forouzanfar T, Kemler MA, Weber WE, Kessels AG, van Kleef M. Spinal cord stimulation in complex regional pain syndrome: Cervical and lumbar devices are comparably effective. $\mathrm{Br}$ J Anaesth 2004; 92:348-353.

26. Robaina FJ, Dominguez M, Diaz M, Rodriguez JL, de Vera JA. Spinal cord stimulation for relief of chronic pain in vasospastic disorders of the upper limbs. Neurosurgery 1989; 24:63-67. 
27. Francaviglia N, Silvestro C, Maiello M, Bragazzi R, Bernucci C. Spinal cord stimulation for the treatment of progressive systemic sclerosis and Raynaud's syndrome. Br J Neurosurg 1994; 8:567-571.
28. Narakas AO. The treatment of brachial plexus injuries. Int Orthop 1985; 9:29-36.

29. Deer T, Masone RJ. Selection of spinal cord stimulation candidates for the treatment of chronic pain. Pain Medicine
2008; 9:82-92.

30. Rosenow JM, Stanton-Hicks M, Rezai AR, Henderson JM. Failure modes of spinal cord stimulation hardware.] Neurosurg Spine 2006; 5:183-190. 